\title{
TERAPIA ASSISTIDA POR ANIMAIS NO AUXÍLIO AO PROCESSO EDUCACIONAL DE CRIANÇAS COM DEFICIÊNCIA INTELECTUAL
}

\author{
Jéssica Daniela de Lins Rovaris* \\ Waléria Henrique dos Santos Leonel**
}

RESUMO: O presente estudo tem por objetivo demonstrar como a prática da terapia assistida por animais pode servir de auxílio ao processo educacional de crianças com deficiência intelectual. A terapia assistida por animais emprega o animal como parte do tratamento, para auxiliar no bem-estar dos pacientes, tendo como princípio a relação entre animais e seres humanos. É notável a falta de estudos específicos nesta área, então divulgar e tornar conhecida essa prática, que tem conquistado espaço em vários lugares, é o objetivo da pesquisa, de modo a auxiliar pedagogos e demais profissionais que atuam juntamente a crianças com deficiência intelectual, para que saibam utilizar essa prática inovadora como uma ferramenta. A metodologia de pesquisa é revisão bibliográfica, constituindo uma busca de pesquisas e resultados sobre o tema, para contemplar um trabalho que possa servir de embasamento para outros, sendo notável o pequeno número de fomento neste campo.

PALAVRAS-CHAVE: Educação; Crianças; Deficiência; Terapia; Animais.

\section{ANIMAL ASSISTED THERAPY FOR THE EDUCATIONAL PROCESS OF CHILDREN WITH INTELLECTUAL DEFICIENCY}

\begin{abstract}
Assisted Therapy with animals may be a help in the educational process of children with intellectual deficiency. The method uses the animals as part of the therapy to help the well-being of patients, foregrounded on the principle of the relationship between animals and humans. Since lack of studies on the subject is great, current paper describes the practice which has acquired notoriety and which will help pedagogues and other professionals that work with children so that they may use this innovation as a tool. Research is based on bibliography on research works and results on the theme. It may be the basis for other works due to the small number of published papers on the subject.
\end{abstract}

KEY WORDS: Education; Children; Deficiency; Therapy; Animals.

\footnotetext{
* Psicóloga, graduada pelo Centro Universitário Unifacvest. Acadêmica do curso de Pedagogia do Centro Universitário de Maringá (UniCesumar), Brasil. E-mail: jessicadanieladelins@hotmail.com

* Mestre em Psicologia pela Universidade Estadual de Maringá. Docente do curso de Pedagogia do Centro Universitário de Maringá (UniCesumar), Brasil.
} 


\section{INTRODUÇÃO}

A presente pesquisa visa apresentar a prática da terapia assistida por animais aplicada ao trabalho com crianças que possuem deficiência intelectual. Tem como objetivo apresentar os desafios vivenciados durante toda a história pelas pessoas com deficiência, pontuar sobre o desenvolvimento da terapia assistida por animais, e como a aplicação da técnica pode auxiliar no desenvolvimento de crianças com deficiência intelectual.

Em um primeiro momento foi compreendida a pessoa com deficiência numa perspectiva sócio-histórica, observando como as mesmas eram vistas em nosso meio social, e todas as dificuldades e preconceitos vivenciados ao longo da história. Também é visto a terminologia correta a ser empregada atualmente, e o conceito de deficiência mental em nossos dias.

Por conseguinte, foi explanada a terapia assistida por animais, o histórico da utilização de animais para o bem-estar humano, o trabalho dos pioneiros na prática, e como a mesma desenvolveu-se até tornar-se prática científica; viu-se também a diferenciação entre terapia assistida por animais (TAA) e atividade assistida por animais (AAA).

Ainda, é observada a prática da TAA/AAA, seus benefícios e também cuidados necessários quanto aos recursos terapêuticos com animais, as modalidades existentes dentro da prática, os benefícios oferecidos especialmente pela equoterapia e pela cinoterapia, e os procedimentos necessários para o bem-estar do animal participante.

Analisou-se, então, a importância da TAA junto ao trabalho com crianças com deficiência mental, os benefícios já apresentados em demais estudos efetuados; e também a importância do papel do pedagogo, demonstrando a necessidade de uma preparação acerca do funcionamento do processo, tanto deste profissional, como dos demais envolvidos, para a prática alcançar os resultados esperados, e possa além de auxiliar as crianças, ser mais uma ferramenta para o trabalho do profissional.

A metodologia utilizada foi de pesquisa bibliográfica, segundo Barros (2000, p.34) "esse modelo de pesquisa é do tipo que se efetua tentando-se resolver um problema ou adquirir conhecimentos a partir do emprego predominantemente de informações advindas de fontes como livros, arquivos e demais documentos". Dessa 
forma, a pesquisa bibliográfica possibilita amplo alcance de informações, além de permitir também a utilização de dados de outros estudos, servindo como auxílio para a construção e definição do objeto de estudo (GIL, 1994).

\section{COMPREENDENDO A PESSOA COM DEFICIÊNCIA NUMA PERSPECTIVA SÓCIO-HISTÓRICA}

A concepção social e cultural da deficiência sofreu transformações importantes no decorrer da história, influenciando as formas de tratamento e atendimento na contemporaneidade. $\mathrm{Na}$ antiguidade clássica, a segregação e abandono das pessoas com deficiência era algo comum e aceitável para a sociedade (SANTOS, 2002). Platão (427-399 A.C) e Aristóteles (384-322 A.C) reconheceram a prática de abandono e morte de pessoas deficientes sob o intuito de ordem social. $\mathrm{Na}$ sociedade espartana, as pessoas com deficiência mental eram consideradas subhumanas, e abandono e extermínio eram aceitos, por estes indivíduos não estarem dentro dos modelos culturais (PESSOTI, 1984 apud LEONEL, 2014).

De acordo com Fonseca (1995), os exorcistas e esconjuradores da Idade Média acreditavam que a deficiência andou sempre ligada a crenças sobrenaturais e demoníacas. Porém, o cristianismo obtinha a postura de piedade diante destas pessoas. Assim, seguindo a concepção cristã, os deficientes passaram de excluídos a então vistos como merecedores de caridade.

No século XVI, Paracelso e Cardano deram o passo inicial em estudos científicos sobre a deficiência. Mas a consolidação científica acerca da deficiência aconteceu apenas no século XIX, com a junção de vários estudiosos. De acordo com Santos (2002, p. 29),

Os estudos de Pinel, Itard, Esquirol, Seguim, Morel, Down, Dugdale, Froebel, Guggenbuehl, entre outros, que passaram a descrever cientificamente a etiologia de cada deficiência numa perspectiva clínica. Cabe ressaltar que, apesar dessas contribuições científicas, a primeira metade do século XX ainda ficou marcada pela atuação do Nazismo no sentido de ter provocado a eliminação bárbara de pessoas com deficiência. Verifica-se que, paralelamente à consolidação da concepção científica da deficiência, ainda hoje ocorrem atitudes 
sociais de marginalização das pessoas com deficiência, semelhantes aquelas vividas na Antiguidade Clássica.

Porém, apesar de tentativas inovadoras com relação à visão de deficiência, a institucionalização em manicômios e asilos foi a principal resposta obtida, constituindo-se em uma fase de segregação, com a justificativa de que o indivíduo seria melhor cuidado e protegido se permanecesse em um ambiente confinado. Juntamente a isto, ocorre a institucionalização escolar obrigatória, porém, a incapacidade escolar de atender a esta demanda gerou conflitos. Mesmo que de maneira lenta, o acesso de pessoas com deficiência à educação vai sendo conquistado (MENDES, 2006).

De acordo com Sassaki (2014), o histórico de atenção educacional para pessoas com deficiência passou por quatro fases: na fase de exclusão, nenhuma atenção educacional foi promovida a estas pessoas, pois as mesmas eram vistas como indignas de tal meio. Na fase de segregação institucional, foram criadas escolas especiais para as pessoas com deficiência, pois as mesmas eram impossibilitas de estar na escola comum. Já na fase de integração, foram criadas as classes especiais, salas de recursos, e os deficientes mais "aptos" já eram encaminhados às escolas comuns. Na última fase, a da inclusão, todos os alunos são colocados na mesma sala, deficientes ou não, e os procedimentos escolares são adaptados para atender a demandas diversas.

A partir desta desinstitucionalização escolar, houve melhor aceitação do deficiente. Porém, muito tempo ainda levou-se para que os mesmos fossem vistos além de suas limitações (LEONARDO, 2008). Segundo Paula (1996), isto aponta para uma sociedade que valoriza demasiadamente os aspectos intelectuais, a competitividade e produção que esse indivíduo deve obter, a beleza física, e também a independência e o individualismo, fazendo com que as pessoas que possuem alguma limitação, seja ela física ou mental, ou que fujam dos padrões estabelecidos pela sociedade, sejam desvalorizadas pelo meio social.

Acerca da terminologia correta a ser empregada às pessoas com deficiência, Sassaki (2002) pontua que o uso correto ou não de termos técnicos não é apenas uma questão semântica ou sem importância; utilizar a terminologia correta é muito importante quando se tratam de temas cercados pelo preconceito. Os termos 
são modificados de acordo com a época e a sociedade em questão, o que pode causar dificuldade tanto para profissionais, como para o público leigo, quanto à terminologia correta a utilizar, e também aumentar a resistência quanto a novas ideias acerca do tema.

Mendonça et al (2014, p. 21) afirmam que "No decorrer dos anos, o conceito de deficiência intelectual passou por diversas definições e terminologias, tais como: oligofrênia, retardo mental, atraso mental, deficiência mental, etc.” Atualmente, o termo correto da condição a ser utilizado é deficiência intelectual.

Diante da colocação dos autores acima, observa-se que a deficiência sempre carregou um estigma de não aceitação, e apesar dos diferentes modos de organização da sociedade ao longo do processo civilizatório, e a concepção diferente do homem em cada uma destas fases, é notável a modificação social da concepção acerca da deficiência intelectual, porém é observável que em todas as épocas demonstrou-se limitação na compreensão da deficiência (LEONEL, 2014).

A compreensão da deficiência intelectual (DI) nos desafia frente ao extenso embasamento teórico na tratativa da temática, dessa forma, buscamos a definição de DI, visando maior entendimento desta parcela da população, conforme o DSM-V (Manual Diagnóstico e Estatístico de Transtornos Mentais), (2014, p. 33).

Deficiência intelectual (transtorno do desenvolvimento intelectual) é um transtorno com início no período do desenvolvimento que inclui déficits funcionais, tanto intelectuais quanto adaptativos, nos domínios conceitual, social e prático. [...] Os vários níveis de gravidade são definidos com base no funcionamento adaptativo, e não em escores de QI, uma vez que é o funcionamento adaptativo que determina o nível de apoio necessário. Além disso, medidas de QI são menos válidas na extremidade mais inferior da variação desse coeficiente.

Pautados nos manuais da área médica, encontramos a deficiência intelectual dividida em níveis: leve, moderado, grave, e profundo. Atualmente, o diagnóstico, presa por descrições globais do indivíduo, e não mais apenas de uma forma fragmentada, por meio de testes, para assim "rotular" o indivíduo com deficiência (VIVALDINI, 2011). A autora ainda aponta que as crianças com deficiência intelectual, em seus diversos níveis, geralmente apontam comprometimentos psicomotores e 
afetivo-emocionais, apresentando problemas de interação social, dificuldades em trabalhos escolares, em manter amizades e brincar com outras crianças em grupo.

É notório, de acordo com o breve recorte do contexto histórico da deficiência, que infelizmente "as pessoas com deficiência intelectual (DI) podem apresentar dificuldades para se inserir na sociedade, pois muitas vezes são vistas como incapazes" (CAPOTE, COSTA, 2011, p. 15).

Porém, na atualidade as pessoas deficientes estão conquistando cada vez mais seu lugar na sociedade. Silva (2011) lembra que a questão de integração e inclusão ainda está longe do ideal, por muitas barreiras existentes como já observadas, porém, o fato de estar sendo discutida já é um grande avanço. Muitas práticas sociais estão sendo criadas para a valorização e inclusão do deficiente, tanto no âmbito escolar, no mercado de trabalho, e também nas universidades. Capote e Costa (2011, p. 4) dizem que "A busca de novos métodos, procedimentos e técnicas é urgente, pois professores, profissionais e familiares necessitam de respostas, suporte e acolhimento".

Dessa forma, práticas inovadoras como a TAA tem como objetivo promover a saúde, o bem-estar e a integração social da criança com deficiência intelectual, podendo ser uma prática efetiva no campo da educação e contribuir para com o avanço e desenvolvimento das crianças com déficit cognitivo.

\section{COMPREENDENDO A TERAPIA ASSISTIDA POR ANIMAIS}

A TAA teve seu primeiro registro no ano de 1792, na Inglaterra, em um centro denominado York Retreat, uma instituição para deficientes mentais ${ }^{3}$ e foi introduzida por William Tuke ${ }^{4}$, onde os pacientes cuidavam de animais. Em 1830, em um hospital inglês denominado Betheem, alguns programas de caridade começaram a perceber que os animais proporcionavam uma atmosfera mais leve para os pacientes com doenças mentais. Em Bethel, na Alemanha, no ano de

\footnotetext{
${ }^{3}$ O termo utilizado atualmente a este público é pessoa com deficiência intelectual. Durante este trabalho serão utilizados outros termos por se tratarem de dados históricos.

${ }^{4}$ William Tuke foi um negociante e filantropo inglês. Seu nome é ligado ao tratamento humanizado de deficientes mentais. Foi o mesmo quem projetou a instituição psiquiátrica York Retreat.
} 
1867, os animais eram utilizados em uma clínica de pacientes epiléticos, onde os mesmos auxiliavam no tratamento desses pacientes. Em 1944 a 1945, a Força Aérea Americana utilizou cães, cavalos e animais de fazenda nos programas terapêuticos para a reabilitação de soldados (DOT'TI $\left.{ }^{5}, 2014\right)$.

Nise da Silveira, psiquiatra junguiana brasileira, foi a grande pioneira da prática em nosso país, sendo seu nome referência no Brasil. Na década de 50 iniciou seu trabalho no Centro Psiquiátrico Pedro II, no Rio de Janeiro. Neste contexto, Nise encontrou uma cadelinha abandonada e faminta no terreno do Centro, tomou-a nas mãos, e então se aproximou do internado o senhor. Alfredo, perguntando-lhe se gostaria de tomar conta daquela cadelinha, com muito cuidado. Respondendo que sim, deram a cachorrinha o nome de Caralâmpia. Depois deste ocorrido, Nise relata vários casos de outros pacientes que se beneficiaram com a presença dos animais (Authausen, 2006).

Silveira (1982, apud CAETANO, 2010, p. 21), em seu livro "Imagens do Inconsciente", publicado no ano de 1982, fala da importância destes coterapeutas.

Excelentes catalisadores são os co-terapeutas não humanos. Desde a adoção da pequena cadela Caralâmpia [...] verifiquei as vantagens da presença de animais no hospital psiquiátrico. Sobretudo o cão reúne qualidades que o fazem muito apto a tornar-se um ponto de referência estável no mundo externo. Nunca provoca frustrações, dá incondicional afeto sem nada pedir em troca, traz calor e alegria ao frio ambiente hospitalar. Os gatos têm um modo de amar diferente. Discretos, esquivos, talvez sejam muito afins com os esquizofrênicos na sua maneira peculiar de querer bem.

Boris Levinson foi um psiquiatra infantil pioneiro na prática da TAA nos Estados Unidos. Percebeu os benefícios do uso de animais com crianças, e no ano de 1962, escreveu seu primeiro artigo, intitulado "O cão como co-terapeuta", no qual nos traz o relato da experiência que teve com seu paciente e um cão, nas seguintes palavras:

${ }_{5}^{5}$ Jerson Dotti é referência no Brasil em estudos sobre Terapia Assistida por Animais. É autor do livro "Terapia e Animais", e por este motivo terá seu nome citado várias vezes durante este estudo. 
Para minha surpresa, a criança não demonstrou medo, ao contrário, envolveu o cão e começou a acaricia-lo. Os pais queriam separa-los, mas assinalei que deixassem a criança. Após um tempo a criança perguntou se o cão sempre brincava com as crianças que vinham ao meu consultório. Tranquilizada diante da minha resposta afirmativa a criança manifestou o desejo de voltar e brincar com o cão. Alguém poderá adivinhar o que teria acontecido com a reação da criança se o cão não estivesse presente naquela manhã? (LEVINSON, 1962, apud AUTHAUSEN, 2006, p. 25)

Atualmente, a prática de utilização de animais como terapeutas é reconhecida cientificamente como terapia assistida por animais. Esta é uma prática que emprega o animal como parte integrante e principal do tratamento a crianças, adolescentes, adultos e idosos, com o objetivo de promover a melhora psíquica, social, cognitiva e física dos pacientes. O seu princípio é que o amor e a amizade entre animais e seres humanos promovem inúmeros benefícios à qualidade de vida do assistido (CAPOTE, COSTA, 2011).

A TAA pode abranger diversos campos, podendo ser utilizada em áreas relacionadas ao desenvolvimento psicomotor e sensorial, tratamento de distúrbios físicos, transtornos mentais e emocionais (CAPOTE, COSTA, 2011).

Segundo Authausen (2006), por ser uma prática que relaciona seres humanos e animais, foi necessária a regulamentação da mesma; dessa forma, um marco importante para sua concretização como método científico foi a determinação da terminologia correta.

Atualmente, as nomenclaturas corretas a serem utilizadas são Animal Assisted Therapy (ATT), traduzida no Brasil por Terapia Mediada por Animais ou Terapia Assistida por Animais, sendo a segunda opção mais utilizada, e Animal Assisted Activity (AAA), termo traduzido para Atividade Mediada por animais, ou Atividade Assistida por Animais. Foi necessária essa diferenciação e regulamentação pelas confusões com outros termos utilizados, como zooterapia, pet terapia etc. Assim, demonstrou-se credibilidade e profissionalismo à realização das atividades da prática (AUTHAUSEN, 2006).

Segundo Volpi e Zadrozny (2012), a TAA é especificamente utilizada por profissionais da saúde, e o animal utilizado será selecionado, treinado e terá rígido 
controle de saúde. O profissional que dirige a prática possui um planejamento, um estudo de cada caso, e uma rotina específica. Nesse sentido, Dotti (2014) contribui afirmando que a TAA envolve serviços de várias áreas, inclusive a médica. Na prática os animais têm o acompanhamento do proprietário ou condutor, e os mesmos têm objetivos e critérios claros quanto ao desenvolvimento do trabalho.

A prática da TAA tem como objetivo a promoção de saúde física, social e emocional e consiste em um processo com metodologia, documentos, planejamento, e avaliações, e todos os avanços são verificados para atingir a meta do programa; possui controle, prontuários e relatórios e pode ser desenvolvida tanto individualmente como em grupos (DOTTI, 2014).

Já a AAA é realizada por um voluntário treinado, que conduz o animal selecionado, treinado e com rígido controle de saúde, até os pacientes, para entretêlos ou distrá́-los. As visitas não necessitam ser rotineiras, e o voluntário não segue um planejamento, nem faz estudo de cada caso (VOLPI, ZADROZNY, 2012).

Dotti (2014) esclarece que a AAA envolve visitação, distração e recreação, podendo ser dirigida por diferentes pessoas, sem um programa oficial. As atividades são desenvolvidas por aproximadamente 01 hora, ou 01h30min, sem ser necessário um dia estabelecido, podendo ocorrer esporadicamente. São atividades que não possuem o resultado de uma análise, e propõem entretenimento e motivação a fim de melhorias na qualidade de vida.

É de extrema importância sabermos que tanto a TAA como a AAA devem ser dirigidas por um grupo multidisciplinar, onde trabalhem juntos diferentes profissionais: veterinários, psicólogos, psiquiatras, pedagogos, fisioterapeutas, adestradores, terapeutas ocupacionais e demais especialistas (SANTOS, 2006).

A mesma autora ainda ressalta que, mesmo constituindo em uma prática dirigida por uma equipe multidisciplinar, e abrangendo desta maneira vários aspectos concomitantes ao indivíduo, em nenhum momento a TAA/AAA substitui as demais modalidades terapêuticas (psicoterapia, fisioterapia, medicina), mas as complementam (SANTOS, 2006).

Segundo Dotti (2014), um dado importantíssimo para ser exposto é que no Brasil temos alguns grupos que desenvolvem o trabalho da TAA/AAA, porém, fazendo comparação com outros países, nos registros dos últimos 40 anos, estamos 
muito aquém destes trabalhos. Dessa forma, pode-se inferir que é necessário com urgência possibilidades de desenvolvimentos nesta área.

De acordo com Capote e Costa (2011), em nosso país existe um bom número de matérias e reportagens acerca da prática, porém geralmente elas se baseiam em pesquisas de programas internacionais. Nota-se a necessidade de fomentação nessa área aqui no Brasil. Porém, os autores revelam que os programas que aqui funcionam, são organizados por pessoas interessadas e comprometidas, que apesar das dificuldades em estabelecer um órgão e conseguir recursos e mão de obra tanto humana quanto animal, realizam a maioria dos programas em instituições para idosos e crianças, como hospitais, escolas e universidades.

\section{VIVENCIANDO A PRÁTICA DA TAA/AAA: BENEFÍCIOS E CUIDADOS NECESSÁRIOS QUANTO AOS RECURSOS TERAPÊUTICOS COM ANIMAIS}

Como observado ao longo da pesquisa, na AAA são reconhecidas cientificamente, deste modo vem sendo adotadas em diversos países, inclusive no Brasil, e nas mais diversas áreas voltadas para os mais diferentes públicos, pois demonstra-se cada vez mais confiabilidade na prática pelos resultados positivos que tem alcançado.

Vários animais podem ser empregados na prática da TAA/AAA, como cães, gatos, cavalos, coelhos, furões, hamsters, porquinhos da Índia, tartarugas, até lhamas, pássaros e peixes. Cada animal possui peculiaridades e área de melhor alcance $\mathrm{e}$ benefícios. Os gatos, por exemplo, são ótimos companheiros para o tratamento com crianças, idosos e pacientes com problemas psíquicos, sendo muito dóceis e carinhosos. Na equoterapia, prática que utiliza cavalos, os principais benefícios são a melhora biopsicossocial, na afetividade, respeito, ganho de força (DOTTI, 2014).

Copetti et al (2007), falando sobre a equoterapia, trazem-nos que os estímulos sensoriais gerados pelos passos do animal, favorecem maior controle motor, reeducação postural, melhoria na percepção espaço-temporal, e aumento do tônus muscular. Graup et al (2006) levantam dados de um estudo feito com crianças com síndrome de Down, no qual observou que a prática trouxe melhorias no equilíbrio 
e estabilidade no andar, como consequência do ajuste de postura que é necessário para cavalgar no animal. Segundo Caetano (2010), a prática da equoterapia permite por meio do sentimento lúdico a interação com o animal, oportunizando condições para recuperação emocional, social, da saúde, e da qualidade de vida do paciente.

Outra prática importante na TAA diz respeito à terapia com cães, conhecida como cinoterapia, que ao ser observada no trabalho com crianças, demonstra contribuições no aumento da socialização, na redução de ansiedade, estresse e solidão, estímulo de troca de afeto etc (MEDEIROS, CARVALHO, 2008). Os mesmos autores fazem ainda uma reflexão social, no qual a relação entre humanos e animais foi estreitando-se, e assim criando laços afetivos. Em uma sociedade onde o individualismo e a solidão são predominantes, a presença do cão minimiza estes sentimentos. Broom e Fraser (2010) ainda pontuam que alterações também ocorreram na vida dos cães por se associarem aos humanos, visto que estes antes eram usados para caça de outros animais, e agora assumem papéis na sociedade humana, despertando afeto nos mesmos. Dotti (2014, p. 22) afirma "De todos os animais eleitos para esse trabalho, o cão, pelo seu temperamento e comportamento, teve no decorrer de toda a pesquisa, estudos e trabalhos na área da A/TAA os melhores resultados nos tratamentos", pautando ser o cão o melhor animal para ser empregado na prática.

A prática da TAA exige cuidados essenciais para a participação do animal, pois o mesmo deve ser avaliado por um veterinário e um psicólogo. O primeiro se responsabiliza em verificar a saúde documental e física do animal, e o segundo pela avaliação do comportamento no que tange à socialização, à obediência e ao temperamento do mesmo. Outro fator concomitante é o fato da atenção necessária ao comportamento do animal durante e após a prática, identificando se o mesmo não demonstra estresse ou irritação, pois pode cansar-se e mudar seu temperamento (DOTTI, 2014).

Visto os inúmeros benefícios apresentados como resultados da prática TAA/ AAA, e também a variedade de animais e modalidades disponíveis à utilização, é preciso atenção à saúde do animal e dar todo o suporte necessário, pois sendo a mesma parte fundamental do processo, necessita de cuidados para apresentar-se saudável. 


\section{A IMPORTÂNCIA DA TAA JUNTO A CRIANÇAS COM DEFICIÊNCIA INTELECTUAL E O PAPEL DO PEDAGOGO}

A partir do estudo, é notável que a convivência do homem com os animais e os benefícios desta relação por toda a nossa história. Hoje, porém, essa relação tem um novo olhar, no qual se tem uma prática reconhecida cientificamente como terapia assistida por animais. No contexto escolar, a inserção de animais na área educacional, para o auxílio e benefício dos alunos aprendizes, não é tão recente como se pensa.

Segundo Godoy e Denzin (2007), no campo da pedagogia, a proposta de inserir animais no espaço escolar já é existente desde os séculos IX e XX, em que Ovide Decroly ${ }^{6}$, ao trabalhar com crianças com alguma limitação, desenvolveu um método de ensino que ficou conhecido como centros de interesse. Nele, os interesses das crianças apareciam de maneira associada e também em contato com o meio, em três momentos: observação, associação e expressão. Decroly procurava colocar as crianças sempre em contato com a natureza, permitindo-as viver as dificuldades de cada fase e a resolvê-las, assim sendo, o conhecimento e contato com a natureza e com diversos seres vivos, como plantas e animais, era importantíssimo. Decroly percebeu que ao utilizar o método de permitir com que as crianças entrassem em contato com a natureza e com diversos seres vivos para resolver desafios e dificuldades, obteve benefícios.

Dessa forma, Godoy e Denzin (2007) trazem-nos que os objetivos da inserção da TAA em escolas consistem no encorajamento dos pedagogos para ensinar sobre o bem-estar dos animais, o estímulo à valorização e consideração de pessoas, pelos animais, meio ambiente, e pela vida. Porém, esse trabalho deve ser muito bem planejado.

Caminhando no campo educacional, adentramos à utilização da prática com crianças com deficiência intelectual. Vivaldini (2011, p. 25) nos faz a seguinte colocação: "O animal é uma preciosa ajuda terapêutica e re-educativa para pacientes

\footnotetext{
${ }^{6}$ Jean-Ovide Decroly foi médico, psicólogo e pedagogo. Foi um dos precursores dos métodos ativos, fundamentados na possibilidade de o aluno conduzir o próprio aprendizado e, assim, aprender a aprender.
} 
com deficiências". A autora, em seu estudo acerca da TAA como uma proposta de inclusão, pautou que as crianças participantes com deficiência intelectual obtiveram como benefício dessa prática educativa o aumento da autoestima, desenvolvimento da coordenação motora, estimulação da linguagem oral, e estímulo da socialização.

Capote (2011) constatou em seu estudo sobre como a TAA poderia influenciar o desenvolvimento psicomotor da criança com deficiência intelectual, que as contribuições para os participantes foram maior motivação, seguimento de regras, alegria, tranquilidade e atenção. As crianças participantes ainda disseram que as atividades que mais gostaram foram jogar bola e brincar com o Luke, o cãozinho terapeuta.

De acordo com Mendonça (2014), crianças com deficiência intelectual, que utilizam a TAA, apresentaram desenvolvimento nas funções físicas, melhorias nas atividades mentais no ambiente escolar, estímulo da memória e consequentemente avanço na aprendizagem. Dessa maneira, Dotti (2014) afirma que o animal pode exercer o papel de catalisador, que expõe a criança a diferentes situações, e assim a mesma cria um senso de si, autocontrole, respeito e gentileza. Ainda o mesmo autor pontua que a interação criança-animal é inata, pois os gestos, a curiosidade, o afago e o contato um com o outro tem significância além das palavras.

No contexto escolar foi observado por Oliveira (2007) que professores ao receberem animais em suas salas de aula notaram efeito tranquilizante em seus alunos, com mais intensidade nos alunos que apresentavam dificuldades de aprendizagem e comportamento; melhorando o comportamento, a concentração e a autoestima com consequente diminuição do estresse.

Logo, para que a prática possa alcançar os inúmeros benefícios que tem a oferecer, faz-se necessário conhecimento e preparação dos profissionais que trabalham com crianças deficientes, sejam eles pedagogos, psicólogos, fonoaudiólogos, terapeutas ocupacionais, entre outros. Dotti (2014) pontua que ao trabalharmos com crianças, devemos estar estruturados e obter conhecimentos e técnicas tanto da pedagogia como da psicologia, pois quanto mais conhecimentos temos acerca do assunto, mais poderemos utilizar para enriquecimento do nosso trabalho e trazer benefícios para as crianças.

Santos (2006) chama a atenção de pedagogos para o papel que podem 
desempenhar junto a esta prática educacional inclusiva. Segundo a autora, a pedagogia é o único curso de nível superior que possui instrumentos, tanto teóricos quanto práticos, para a formação de docentes que estejam preparados para a educação e técnica inclusivas.

Portanto, é observável que tanto a TAA como a AAA podem trazer ricas contribuições, enquanto prática terapêutica, para auxiliar no trabalho pedagógico e consequentemente, ao desenvolvimento do aluno com deficiência intelectual. E fazse necessário também que profissionais que atuam junto a essas crianças possuam conhecimento acerca da mesma, para utilizar a prática como uma ferramenta de auxílio ao enriquecimento do trabalho.

\section{CONSIDERAÇÕES FINAIS}

Ao longo desta pesquisa, observou-se que desde o início da civilização a dificuldade de aceitação e inserção da pessoa com deficiência, particularmente a deficiência intelectual, esteve presente, apesar dos diferentes modos de organização da sociedade ao longo do tempo. Atualmente, as pessoas com deficiência estão conseguindo romper paradigmas e estereótipos, e assim conquistar seu lugar no meio social, porém isso ocorre de maneira lenta. É notável a necessidade de novos métodos de suporte e inserção social para as pessoas com deficiência. A TAA/AAA tem um longo histórico, com seu primeiro registro oficial na Inglaterra no ano de 1792, por conseguinte em demais países, e na década de 50 com início no Brasil com a pioneira Nise da Silveira.

A prática tem como princípio o amor e a amizade entre seres humanos e animais, e desta forma, apresenta inúmeros benefícios físicos, emocionais e cognitivos. A prática tem conquistado cada vez mais espaço por demonstrar ser uma técnica científica eficaz. No trabalho com crianças com deficiência intelectual, estudos demonstraram melhorias na autoestima, desenvolvimento da coordenação motora, melhoria na socialização, melhoria nas atividades mentais e avanço na aprendizagem, entre outros.

Porém percebe-se a necessidade de preparo dos diversos profissionais que 
possam atuar junto à prática na equipe multidisciplinar, pois para que a mesma possa alcançar seus objetivos, é necessário conhecimento e preparação dos profissionais que trabalham junto a crianças com deficiência intelectual. É notável que o Brasil esteja muito aquém dos demais países no desenvolvimento e apoio à terapia assistida por animais, e por meio deste estudo as autoras buscam embasar demais trabalhos para fomentação desta área tão rica e com tanto conteúdo a ser aprofundado.

\section{REFERÊNCIAS}

ALTHAUSEN, S. Adolescentes com síndrome de Down e cães: compreensão e possibilidades de intervenção. Dissertação (Mestrado), São Paulo, 2006.

BARROS, A. J. P. Fundamentos de metodologia: um guia para a iniciação científica. 3. ed. São Paulo: Makron Books, 2000.

BROOM, D. M.; FRASER, A. F. Comportamento e bem-estar de animais domésticos. 4. ed. Barueri, SP: Manole, 2010.

CAETANO, E. C. S. As contribuições da TAA: terapia assistida por animais à psicologia. Monografia (Trabalho de conclusão de curso) - Universidade do Extremo Sul Catarinense, Criciúma, 2010.

CAPOTE, P. S. O.; COSTA, M. P. R. Terapia Assistida por Animais (TAA): aplicação no desenvolvimento psicomotor da criança com deficiência intelectual. São Carlos: Ed. da UFSCar, 2011.

COPETTI, F. et al. Comportamento angular do andar de crianças com síndrome de Down após intervenção com equoterapia. Revista brasileira de fisioterapia, v 11, n. 6, p. 503-507, nov./dez. 2007.

DOTTI, J. Terapia e Animais. São Paulo: Livrus, 2014.

DSM-V. Manual diagnóstico e estatístico de transtornos mentais. Porto Alegre: Art Med, 2014. 
FONSECA, V. da. Educação especial: programa de estimulação precoce: uma introdução as ideias de Feuerstein. Porto Alegre: Artes Médicas, 1995.

GRAUP, S. et al. Efeito da equiterapia sobre o padrão motor da marcha em crianças com síndrome de Down: uma análise biomecânica. Revista Digital, Buenos Aires, v. 11, n. 96, mayo 2006.

GODOY, A. C. S.; DENZIN S. S. Atividades assistida por animais: aspectos revisivos sob um olhar pedagógico. Artigo, 2007.

GIL, A. C. Como elaborar projetos de pesquisa. 3. ed. São Paulo: Atlas, 1994.

LEONARDO, N. S. T. Inclusão escolar: um estudo acerca da implantação da proposta em escolas públicas. Revista semestral da associação brasileira de psicologia escolar e educacional (ABRAPEE), v. 12, n. 2, 2008.

\section{MEDEIROS, A. J. S.; CARVALHO, S. D. Terapia assistida por animais a} crianças hospitalizadas: revisão bibliográfica. Campinas, SP: Departamento de enfermagem, Faculdade de Ciências Médicas, Universidade Estadual de Campinas, 2008.

MENDES, E. G. A radicalização do debate sobre inclusão escolar no Brasil. Revista Brasileira de Educação, Rio de Janeiro, v. 11, n. 33, 2006.

MENDONÇA, M. E. F. et al. Terapia Assistida por cães no desenvolvimento socioafetivo de crianças com deficiência intelectual. Periódico. 2014.

LEONEL, W. H. S. O processo de escolarização do deficiente intelectual da educação básicas e os desafios da prática docente: um debate relevante ao ensino superior. Dissertação de Mestrado. Maringá, 2014.

OLIVEIRA, G. N. Cinoterapia: benefícios da interação entre crianças e cães. Artigo. 2007.

PAULA. L. A. L. Ética, cidadania e educação especial. Artigo. Rio de Janeiro, 1996.

SANTOS, J. B. A "dialética de exclusão/inclusão" na história da educação de "alunos 
com deficiência". Revista da FAEEBA - Educação e Contemporaneidade, Salvador, v. 11, n. 17, p. 27-44, jan./jun. 2002.

SANTOS, K. C. P. T. Terapia Assistida por Animais: uma experiência além da ciência. São Paulo: Paulinas, 2006.

SASSAKI, R. K. Terminologia sobre deficiência na era da inclusão. Revista Nacional de Reabilitação, São Paulo, v.5, n.25, p.5-14, mar./abr. 2002.

SASSAKI, R. K. Paradigma da inclusão e suas implicações educacionais. 2014.

SILVA, C. M. B. L. Atividade assistida por animais: uma proposta de inclusão educacional com a utilização de animais de estimação. Monografia (Especialização em desenvolvimento humano, educação e inclusão) - Faculdade UAB/UnB, Brasília, 2011.

VIVALDINI, V. H. Terapia Assistida por Animais: uma abordagem lúdica em reabilitação clínica de pessoas com deficiência intelectual. Dissertação (Mestrado) São Bernardo do Campo, 2011.

VOLPY, D.; ZADROWSKY, V. G. P. Benefícios da TAA: uma contribuição da psicologia. Trabalho de conclusão de curso. Universidade Regional de Blumenau. Blumenau, 2012.

Recebido em: 08/04/2018 Aceito em: 26/09/2018 